\title{
Adsorption of Zn (II) on Acacia Tortilis Leaves Treated with Sulfuric Acid: kinetic studies
}

\author{
Somaya Meftah ${ }^{1}$ and Mohamed Ackacha ${ }^{2}$
}

\begin{abstract}
In the present work, the potential use of Acacia tortilis leaves to remove $\mathrm{Zn}$ (II) from water media was evaluated. In case to activate the surface of Acacia tortilis leaves, some acids such as sulfuric, phosphoric and hydrochloric of $0.1 \mathrm{meq} / \mathrm{ml}$ were tried. High adsorption capacity was obtained when sulfuric acid was used. Kinetic data was measured in batch condition. The effect of some parameters such as: initial $\mathrm{pH}$, adsorbent dosage and contact time on the adsorption of $\mathrm{Zn}$ (II) has been studied. $\mathrm{Zn}$ (II) adsorption was initial $\mathrm{pH}$, adsorbent dosage and time contact dependent. It has been found that the adsorption capacity of $\mathrm{Zn}(\mathrm{II})$ on Acacia tortilis leaves increased as initial $\mathrm{pH}$ increased and rich equilibrium at $\mathrm{pH} 4$. On the other hand, the adsorption capacity of $\mathrm{Zn}$ (II) decreased as adsorbent dosage increased. The maximum adsorption capacity of $\mathrm{Zn}(\mathrm{II})$ was found to occur after two hours. Three kinetic models including fist order, pseudo second order and intra particle diffusion were selected to follow the adsorption process. The process follows a pseudo second order. The following parameters used in this research are constant: contact temperature, $25^{\circ} \mathrm{C} \pm 1$; stirring speed, $400 \mathrm{rpm}$; $\mathrm{Zn}$ (II) concentration, $400 \mathrm{mg} / \mathrm{l}$ and adsorbent size, less than $90 \mu \mathrm{m}$.
\end{abstract}

Keywords--Acacia Tortilis, First Order, Pseudo Second Order, Intra Particle Diffusion

\section{INTRODUCTION}

$\mathrm{Z}^{\mathrm{n}}$ $\mathrm{N}$ (II) may be found in wastewater discharges from acid mine drainage, galvanizing plants, natural ores and from municipal wastewater treatment plant discharges. $\mathrm{Zn}$ (II) travels through the food chain via bioaccumulation. Hence, there is significant interest regarding $\mathrm{Zn}$ (II) removal from wastewater streams [1]. The World Health Organization (WHO) recommends a maximum acceptable concentration of $\mathrm{Zn}$ (II) of $3 \mathrm{mg} / \mathrm{l}$ in drinking water [2]. Hence, the presence of $\mathrm{Zn}$ (II) in water environment is one of the most serious worldwide environmental problems [3]. Conventional methods for removing $\mathrm{Zn}$ (II) include electrodialysis, precipitation, solvent extraction, membrane separation and ion exchange have been reported in literature [2]. Since all these methods have various disadvantages, specifically, high operating cost, incomplete removal, or the high energy consumption. It is therefore a low cost techniques is necessary.

A sorption processes using agricultural materials can be used for waste water treatment because they are cheap, simple and free sludge [4].

Faculty of Science, Sebha University, Libya
In this regard, a wide variety of dead biomass such as sawdust, peanut shell and tree fern are being considered as adsorbents of heavy metals for treatment of industrial and domestic wastewaters as well as natural waters, including drinking water [5].

In this work, the sorption of $\mathrm{Zn}$ (II) from water media by activated Acacia tortilis leaves with sulfuric acid was investigated. Influence of several parameters such as: initial $\mathrm{pH}$, adsorbent dosage and contact time on the adsorption of $\mathrm{Zn}$ (II) has been studied. Three simplified kinetic models including fist order, pseudo second order and intra particle diffusion were selected to follow the adsorption process.

\section{EXPERIMENTAL METHODS}

\subsection{Reagents, Instruments And Solutions}

The following chemicals were used for the kinetic studies for adsorption of $\mathrm{Zn}$ (II) onto the surface of Acacia tortilis leaves. Zinc acetate, hexa methylene tetra amine (EDTA), xylenol orange were reagent grade chemicals and they obtained from Merck, Germany. Sulfuric acid, phosphoric acid, hydrochloric acid, acetic acid and ammonium hydroxide were also reagent grade chemicals and they procured from BDH, England.

The oven of Naber model was obtained from Germany. The sensitive balance was obtained from Mettler, China. The $\mathrm{pH}$ meter of 3505 model was procured from Jenway, England. The shaker water bath was obtained from Clifon, Italy.

Zinc stock solution of $1000 \mathrm{mg} / \mathrm{l}$ was prepared by dissolving the required amount of zinc acetate in double distilled water. Working solutions were prepared by dilution of stock solution.

\subsection{Adsorption Preparation}

The Acacia tortilis leaves was collected from sebha area at south of Libya, washed with double distil water, dried at room temperature for one day and dried in oven at $950 \mathrm{C}$ for one hour. In order to activate the surface of adsorbent, three selected acids such as sulfuric, phosphoric and hydrochloric acid were tried. One gram of dried Acacia tortilis leaves was added to $20 \mathrm{ml}$ of each acid $(0.1 \mathrm{meq} / \mathrm{ml})$ in a $50 \mathrm{ml}$ stoppered glass bottles. The mixture in each bottle was mixed using shaker water bath at $60^{\circ} \mathrm{C}$, filtered, dried in oven at $95^{\circ} \mathrm{C}$ then stored in a plastic containers for farther use. The optimum conditions to adsorb $\mathrm{Zn}$ (II) onto Acacia tortilis leaves treated with mentioned acids as follows: initial $\mathrm{pH}, 4$; adsorbent dosage, $0.02 \mathrm{~g}$; Zn(II) concentration, $400 \mathrm{mg} / \mathrm{l}$; stirring speed, $400 \mathrm{rpm}$ and contact time, 2 hours. 


\subsection{Batch Adsorption Studies}

Generally, the effects of initial $\mathrm{pH}$, adsorbent dosage and contact time on adsorption of $\mathrm{Zn}$ (II) were performed in conical flasks by stirring a certain amount of activated Acacia tortilis leaves with $100 \mathrm{ml}$ of $\mathrm{Zn}(\mathrm{II})$ solutions. The $\mathrm{pH}$ of solutions was varied from 2 to 6 and contact time was varied from 15 to 150 minute. The concentration of $\mathrm{Zn}$ (II) solution were determined by titration with ethylene diamin tetra acetic acid using xylenol orange as indicator. The constant parameters used in this research as follows: contact temperature, $25 \mathrm{oC} \pm 1$; stirring speed, $400 \mathrm{rpm}$; $\mathrm{Zn}(\mathrm{II})$ concentration, $400 \mathrm{mg} / \mathrm{l}$ and adsorbent size, less than $90 \mu \mathrm{m}$.

\section{$2.4 \mathrm{Zn}(\mathrm{II})$ removal}

The amount of $\mathrm{Zn}(\mathrm{II})$ adsorbed, $\mathrm{q}_{\mathrm{e}}(\mathrm{mg} / \mathrm{g})$ was determined by using the following expression [1]:

$$
q_{e}=\frac{\left(C_{o}-C_{e q}\right) V}{W}
$$

Where $\mathrm{C}_{\mathrm{o}}$ and $\mathrm{C}_{\mathrm{eq}}$ are $\mathrm{Zn}$ (II) concentration (mg/l) before and after adsorption, respectively, $\mathrm{V}$ is the volume of $\mathrm{Zn}$ (II) solution (1), W is the weight of Acacia tortilis leaves ( $\mathrm{g}$ ).

\section{RESULTS AND DISCUSSION}

\subsection{Activation of Acacia Tortilis leaves}

Table 1 shows the adsorption capacity of $\mathrm{Zn}$ (II) by the use of sulfuric, phosphoric and hydrochloric acid. It can be observed that, high adsorption capacity of $\mathrm{Zn}$ (II) was obtained when sulfuric acid was used.

\section{TABLE I}

THE OBTAINED AdSORPTION CAPACITIES USING DifFERENT ACIDS

\begin{tabular}{l|l}
\hline \hline Type of acid & ge(mgg) \\
\hline Sulfuric & 309.56 \\
Phosphoric & 214.75 \\
Hydrochloric & 82.25 \\
\hline \hline
\end{tabular}

\subsection{Effect of $p H$}

The effect of $\mathrm{pH}$ on adsorption capacity of $\mathrm{Zn}$ (II) by Acacia tortilis leaves was evaluated within the $\mathrm{pH}$ range of 26 (Figure 1). It was found that the adsorption capacity increased from $30.25 \mathrm{mg} / \mathrm{g}$ to $235.22 \mathrm{mg} / \mathrm{g}$ with increase in $\mathrm{pH}$ from 2 to 4 . Hence, the $\mathrm{pH}$ of 4 was found as optimum $\mathrm{pH}$ for adsorption of $\mathrm{Zn}$ (II) onto Acacia tortilis leaves. These phenomena can be explained as following: at low $\mathrm{pH}$ the hydrogen ion concentration is too high therefore it is difficult for ion-exchange to take place. On the other hand, increasing of $\mathrm{pH}$ produced a low hydrogen ion concentration hence it is so easy for ion-exchange between the active sites of Acacia tortilis particles and $\mathrm{Zn}$ (II) to take place. It is also observed from Figure 1 that, the adsorption capacity is decreased after $\mathrm{pH}$ 4. This is due to the precipitation of $\mathrm{Zn}(\mathrm{II})$ as hydroxides [7].

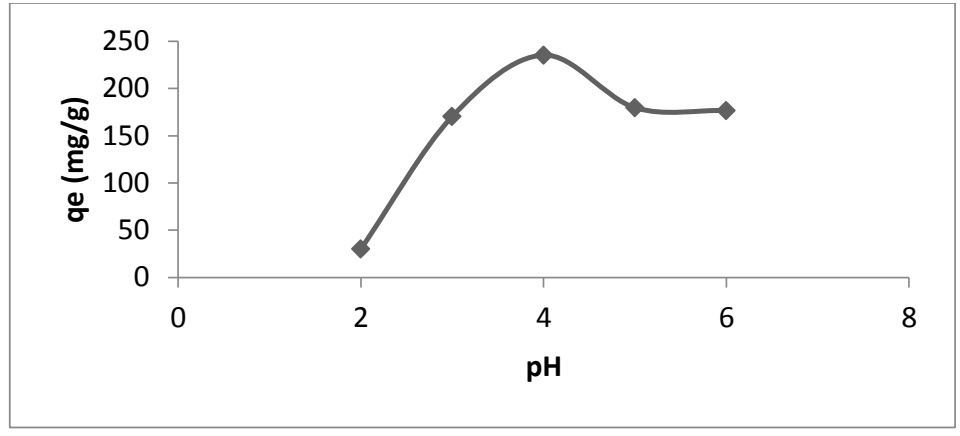

Fig. 1: Effect of $\mathrm{pH}$ on adsorption capacity of $\mathrm{Zn}(\mathrm{II})$

\subsection{Effect of Adsorbent Dosage}

As shown in Figure 2, the adsorption capacity of $\mathrm{Zn}(\mathrm{II})$ decreased from 235.32 to 32.73 with increase in adsorbent dosage from $0.2 \mathrm{~g} / \mathrm{l}$ to $1 \mathrm{~g} / \mathrm{l}$. This phenomena is mainly due to the overcrowding of adsorbent particles and also due to the competition among zinc ions onto Acacia tortilis surface [8].

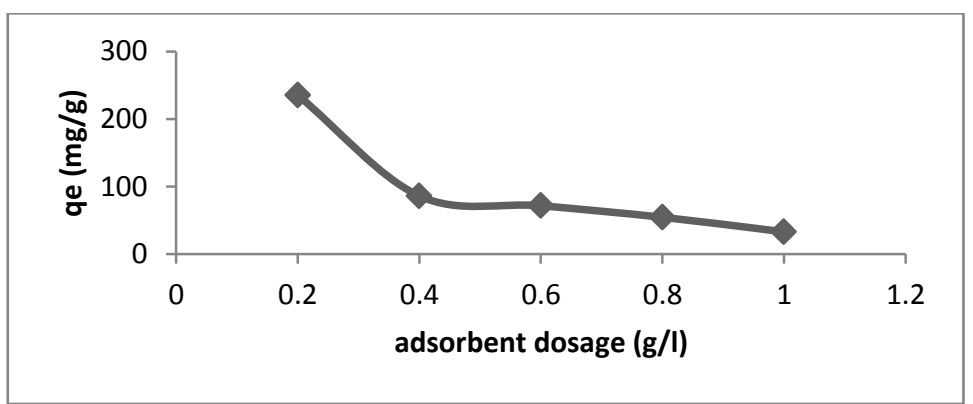

Fig. 2: Effect Of Adsorbent Dosage On Adsorption Capacity Of $\mathrm{Zn}$ (Ii)

\subsection{Effect of Contact Time}

Figure 3 shows the effect of contact time on the adsorption of $\mathrm{Zn}$ (II). The experimental data indicated that the adsorption capacity of $\mathrm{Zn}$ (II) was found to increase with increasing contact time reached maximum value of $187.25 \mathrm{mg} / \mathrm{g}$ after 2 hours and then no further significant increase was observed.

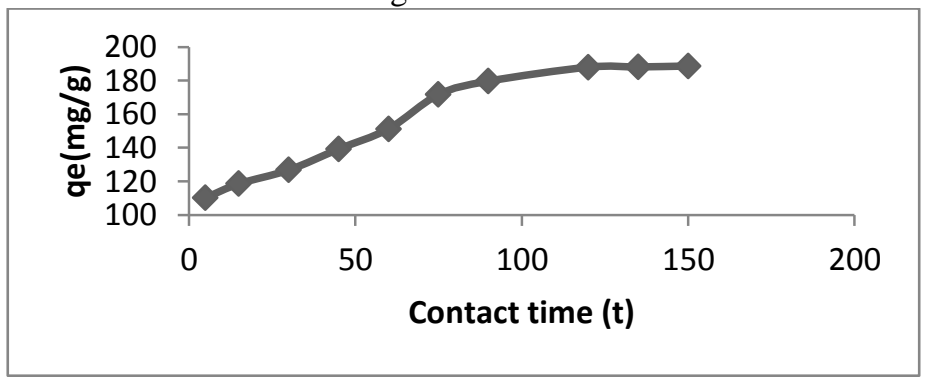

Fig. 3: Effect Of Contact Time On Adsorption Capacity Of Zn(II)

\subsection{Kinetic Models}

The adsorption kinetics of $\mathrm{Zn}$ (II) were tested using first-order, pseudo second-order and intra particle diffusion equations.

The first-order equation is shown below [9]: 


$$
\log \left(q_{e}-q_{t}\right)=\log q_{e}-\frac{K_{1}}{2.303} t
$$

Where $\mathrm{q}_{\mathrm{t}}$ refer the amount of $\mathrm{Zn}(\mathrm{II})$ adsorbed per unit weight of adsorbent $(\mathrm{mg} / \mathrm{g})$ at time $\mathrm{t}(\mathrm{min}) . \mathrm{K}_{1}(1 / \mathrm{min})$ is the rate constant of the first-order sorption. A plot of $\log \left(\mathrm{q}_{\mathrm{e}}-\mathrm{q}_{\mathrm{t}}\right)$ versus $\mathrm{t}$ gives the result shown in Fig. 4. The values of $\mathrm{K}_{1}$, experimental adsorption capacity ( $\mathrm{q}_{\mathrm{e}} \mathrm{exp}$.) and calculated adsorption capacity ( $\mathrm{q}_{\mathrm{e}} \mathrm{cal}$.) are presented in Table 2

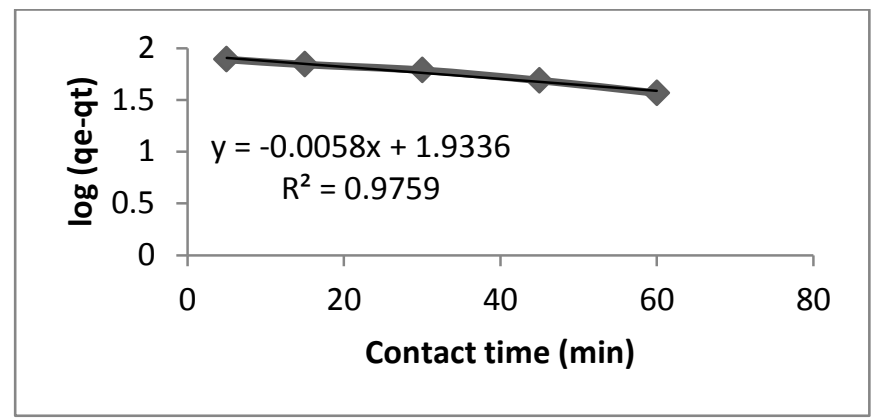

Fig. 4: First Order Kinetic Plot For Adsorption Of Zn(II)

TABLE II

First ORDER PARAMETERS For AdSORPTION OF ZN(II)

\begin{tabular}{llll}
\hline \hline$g_{e}$ exp. & gecl. $_{e}$ & $\mathrm{~K}_{1}(\mathrm{lmin})$ & $\mathrm{R}^{2}$ \\
\hline 187.25 & 85.82 & 0.0134 & 0.9759 \\
\hline \hline
\end{tabular}

The pseudo second-order equation can be written as [9]:

$$
\frac{t}{q_{t}}=\frac{1}{K_{2} q_{e}{ }^{2}}+\frac{1}{q_{e}} t
$$

Where $\mathrm{K}_{2}$ (g/mg.min) is the rate constant of the pseudo second order sorption. The equilibrium adsorption capacity and the pseudo second order rate constant were determined experimentally from the slop and intercept of plot t/qt versus $t$ (Fig. 5). The calculated correlations $\left(\mathrm{R}^{2}\right)$ are closer to unity for pseudo-second order kinetic model; Therefore the adsorption kinetics are favorably by the pseudo-second order rather then the first order for $\mathrm{Zn}(\mathrm{II})$ adsorption. The $\mathrm{K}_{2}$ and $\mathrm{q}_{\mathrm{e}}$ values for the pseudo-second order kinetic, calculated from Fig. 5 are listed in Table 3. By comparing the $\mathrm{q}_{\mathrm{e}}$ exp. and $\mathrm{q}_{\mathrm{e}} \mathrm{cal}$. of the two kinetic models, the pseudo second order kinetic model seems to be best fitted for the experiment because the values of $\mathrm{q}_{\mathrm{e}} \mathrm{exp}$. and $\mathrm{q}_{\mathrm{e}} \mathrm{cal}$ are close together.

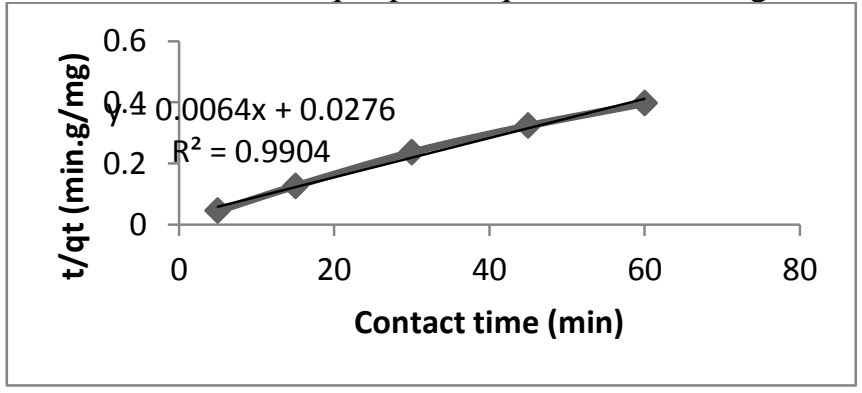

Fig. 5: Pseduo second order kinetic plot for adsorption of $\mathrm{Zn}(\mathrm{II})$
TABLE III

PSEDUO SECOND ORDER PARAMETERS FOR ADSORPTION OF ZN(II)

\begin{tabular}{llll}
\hline \hline $\mathrm{g}_{\mathrm{e}}$ exp. & $\mathrm{g}_{\mathrm{a}}$ cal. & $\mathrm{K}_{2}$ (g/mg.mim)) & $\mathrm{R}^{2}$ \\
\hline 187.25 & 156.26 & 0.0015 & 0.9904 \\
\hline \hline
\end{tabular}

The intra particle diffusion is the most common technique used for confirming the adsorption mechanism in the adsorption process [10]. This model of Weber and Morris is shown as:

$$
q_{t}=K_{p} t^{1 / 2}+C
$$

Where $K_{p}$ is the intra particle diffusion rate constant, $\mathrm{mg} / \mathrm{g} . \mathrm{min}$. and $\mathrm{C}$ is the boundary layer thickness. The linear plots of $\mathrm{q}_{\mathrm{t}}$ versus $\mathrm{t}^{1 / 2}$ as shown in Fig. 6 is probably due to the intra particle diffusion. This plots is not passed through the origin points indicating that, the pore diffusion may not be only the rate-determine step in the removal of $\mathrm{Zn}$ (II) [11]. The slop and intercept of the linear portion represents $K_{p}$ and boundary layer thickness, respectively. The values of $\mathrm{K}_{\mathrm{p}}$ and $\mathrm{R}^{2}$ are listed in Table 4 . These results suggest that the mechanism of $\mathrm{Zn}$ (II) onto the surface of Acacia tortilis leaves was carried out by two steps: adsorption and intra particle diffusion.

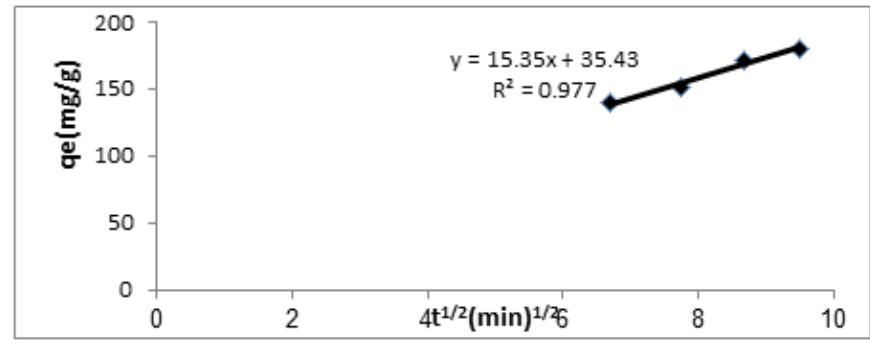

Fig. 6: Intra particle diffusion kinetic plot for adsorption of $\mathrm{Zn}(\mathrm{II})$

TABLE IV

INTRA PARTICLE DifFUSION PARAMETERS FOR ADSORPTION OF ZN(II)

\begin{tabular}{lll}
\hline \hline $\mathrm{Kp}(\mathrm{mg} / \mathrm{g} \cdot \mathrm{min})$ & $\mathrm{C}$ & $\mathrm{R}^{2}$ \\
\hline 15.35 & 35.43 & 0.997 \\
\hline \hline
\end{tabular}

\section{IV.CONCLUSION}

From the experimental results, it was concluded that the maximum adsorption capacity of $\mathrm{Zn}$ (II) ions from aqueous solution occurred when sulfuric acid was used as activator rather than hydrochloric and phosphoric acids. The maximum adsorption capacity was obtained at $\mathrm{pH} 4$ after 2 hours. The adsorption capacity of $\mathrm{Zn}$ (II) was $\mathrm{pH}$, adsorbent dosage and contact time dependent. Batch experiments have shown that the adsorption process can be better described by pseudo second order kinetic model and can be controlled by adsorption and intra particle diffusion.

\section{REFERENCES}

[1] H. N. Bhatti, B. Mumataz, M. A. Hamif, and R. Nadeem, "Removal of $\mathrm{Zn}$ (II) ions from aqueous solution using Moring oleifera lam," Process Biochemistry, vol. 42, pp. 547-553, October 2006. http://dx.doi.org/10.1016/j.procbio.2006.10.009

[2] M. H. Kalavothy, and L. R. Miranda, "Moringa oleifera - a solid phase extraction for the removal of copper, nickel and zinc from aqueous solutions," Chemical Engineering Journal, vol. 158, pp. 188-199, December 2009. http://dx.doi.org/10.1016/j.cej.2009.12.039 
[3] C. Yang, J. Wang, M. Lei, G. Xie, G. Zeng, and S. Luo, "Biosorption of Zinc(II) from aqueous solution by dried activated sludge," Journal of Environmental Sciences, vol. 22(5), pp. 675-680, September 2009. http://dx.doi.org/10.1016/S1001-0742(09)60162-5

[4] M. Horsfall, and A. A. Abia, "Sorption of cadmium(II) and zinc(II) ions from aqueous solutions by cassava waste biomass (Manihot sculenta cranz)," Water Research, vol. 37, pp. 4913-4923, August 2003. http://dx.doi.org/10.1016/j.watres.2003.08.020

[5] F. Al-Tohami, M. A. Ackacha, R. A. Belaid, and M. Hamaali (January 2013). Adsorption of $\mathrm{Zn}$ (II) ions from aqueous solutions by noval adsorption: Ngella sativa seeds. Procedia APCBEE. [online]. 5, pp. 400-404. Available: http://WWW.halcyan.com/journals/21ps03-vimar

[6] F. Y. Wang, H. Wang, and J. Wei Ma, "Adsorption of cadmium(II) ions from aqueous solution by a new low cost adsorbent Bamboocharchol," Journal of Hazardous Material, vol. 177, pp. 300-306, December 2009. http://dx.doi.org/10.1016/j.jhazmat.2009.12.032

[7] H. Lalhruaitluanga, K. Jayaram, M. N. V. Prasad, and K. K. Kumar, "Lead adsorption from aqueous solutions by raw and activated charcoals of Melocanna baccifera roxburgh (Bamboo)- a comparative study," Journal of Hazardous Material, vol. 175, pp. 311-318, October 2010.

http://dx.doi.org/10.1016/j.jhazmat.2009.10.005

[8] R. Cong, Y. Ding, H. Liu, Q. Chen, and Z. Liu, "Lead biosorption and desorption by intact and pretreated spirulina maxima biomass," Chemosphere, vol. 58, pp. 124-130, August 2005.

[9] R. Nadeem, M. H. Nasir, and M. S. Hanif, "Pb(II) sorption by acidically modified cicer arienn biomass," Chemical Engineering, vol. 150, pp. 40-48, December 2009. http://dx.doi.org/10.1016/j.cej.2008.12.001

[10] W. S. W. Ngah, and K. M. Hanafiah, "Adsorption of copper on rubler (Hevea brasiliensis) leaf powder: kinetic, equilibrium and thermodynamics studies," Biochemical Engineering Journal, vol. 39, pp. 521-530, November 2007. http://dx.doi.org/10.1016/j.bej.2007.11.006

[11] M. a. Ackacha, "Removal of $\mathrm{Pb}$ (II) from aqueous solution by Portulaca oleracea leaves: kinetic, equilibrium and thermodynamic studies," American Journal of Analytical Chemistry, vl 4, pp. 27-32, July 2013. 